\author{
Asian Journal of \\ Medical and Biological Research \\ ISSN 2411-4472 (Print) 2412-5571 (Online) \\ www.ebupress.com/journal/ajmbr
}

\title{
Article Occurrence of enteric parasites and their risk factors among the female
inhabitants of lower socioeconomic groups in Dhaka city
}

\author{
Mt. Tahmina Karim*, Hamida Khanum and Sharmin Musa \\ Department of Zoology, University of Dhaka, Dhaka 1000, Bangladesh \\ *Corresponding author: Mt. Tahmina Karim, Department of Zoology, University of Dhaka, Bangladesh. Phone: \\ +8801618142196; E-mail: karim_tahmina@yahoo.com
}

Received: 09 November 2018/Accepted: 28 December 2018/ Published: 30 December 2018

\begin{abstract}
The present study was conducted to investigate the intestinal parasites. A total of 900 female inhabitants of lower socioeconomic groups in Dhaka city were examined during Sep 2013 to Aug 2015, prevalence of gastrointestinal parasitic infestation was $66.22 \%$ and 26 parasite species were identified, of which ten species were protozoans, six cestodes, four trematodes and six nematodes. Prevalence of nematoda was the highest $(57.55 \%)$, then cestode $(38.67 \%)$, protozoa (19.22\%) and lowest was found in trematode $(4.11 \%)$. Entamoeba histolytica (10.44\%) indicates severe faecal contamination among protozoan parasites, while in cestodes Hymenolepis nana (22.78\%), in trematodes Fasciolopsis buski (2.11\%) and in nematodes Ascaris lumbricoides (38\%) were highly prevalent. In twelve study areas, the highest prevalence was found in Kamrangichar $(87.5 \%)$ and children of age group 1-15 years $(75.65 \%)$ were mostly affected by intestinal parasite.
\end{abstract}

Keywords: intestinal parasites; lower socioeconomic groups; prevalence; intestinal parasites

\begin{abstract}
1. Introduction
Intestinal parasitic infections are the most prevalent in the world, with an estimation of 3.5 billion people infected and 450 million ill (WHO, 2001). While mortality from enteric helminths and protozoa is relatively low, morbidity and the indirect effects of apparently asymptomatic infections have a substantial impact on health and quality of life. The World Bank (1993) estimates the global burden of disease from geohelminth infections (A. lumbricoides, T. trichiura and hookworm) to be 2.4 million DALYs. In Latin America, the Pan American Health Organization (PAHO) (1997) estimates that helminth infections affect between $20 \%$ and 30\% of the general population, with prevalence as high as $60-80 \%$ in endemic areas. In Bangladesh, among the helminthes and protozoan parasites, A. lumbricoides, A. duodenale, T. trichiura, E. vermicularis and E. histolytica, G. lamblia are common (Kuntz 1960; Islam et al., 1975; Saha and Chowdhury, 1981; Banu et al., 2003; D'Silva et al., 2003; Uddin et al., 2005; Khanum et al., 2008).

Parasitic diseases continue to cause significant morbidity and mortality throughout the world irrespective of the patient's immune status. It is estimated that in developing regions of the world, there are approximately 340 parasite species capable of infecting humans (Garcia, 2001). Diarrhoeal diseases are extremely common in the developed and developing worlds, affecting millions of individuals each year (Guerrant et al., 1990). In Bangladesh, one third of the total child death burden is due to diarrhoea (Victora et al., 1993). Every year, a rural child suffers on average from 4.6 episodes of diarrhoea, from which about 230,000 children die (Mitra, 1994). The intestinal parasitic infections persist and flourish wherever poverty, improper hygiene, lack of access to clean drinking water, low standards of community and individual sanitation and poor health education, insufficient health care and overcrowding are entrenched (Khanum et al., 2010). Intestinal protozoan infections are even more prevalent; Entamoeba histolytica is one of the deadly species and is associated with pathological abnormalities in liver and large bowel in human body (Khanum et al., 2010), and is estimated to cause severe
\end{abstract}


disease in 48 million people, killing 70 thousand each year (WHO, 2002). G. intestinalis is the most common protozoan infection of the intestinal tract. Many countries, especially developing countries, show a high infection rate of giardiasis (Sprong et al., 2009). Trichuriasis is a potentially serious disease that can cause colitis (inflammation of the colon), chronic iron deficiency anaemia and chronic dysentery (Bundy and Cooper, 1989). Hymenolepis nana is the most common parasitic cestode prevalent globally (Pillai and Kain, 2003). There were around 1000 million cases of ascariasis due to Ascaris lumbricoides, and 500 million cases of Trichuris trichiura infection worldwide (WHO, 1990 and Bundy et al., 1992).

The aim of this study is to estimate the prevalence of intestinal parasitic infestation. In developing countries like Bangladesh intestinal worms are really threats to child and adolescents health. Although the intestinal helminthiasis is extremely wide spread in Bangladesh, they do not always cause immediate fatalist, acute illness or disabilities, so their presence has long been ignore and neglected to the people's mind (Khanum et al., 2008, 2010).

\section{Materials and Methods}

\subsection{Study design}

A cross sectional study was carried out during September 2013 through August 2015 among 900 female inhabitants of lower socioeconomic groups in twelve areas of Dhaka city. The age groups were categorized into 4 major groups: Children ( 1 to $15 \mathrm{yrs}$ ), Adult (16 to $35 \mathrm{yrs}$ ), Middle age (36 to $50 \mathrm{yrs)}$ and Old age (51 to 70 yrs). To study the prevalence of intestinal helminthes, stool samples were collected and processed by Formolether concentration technique.

\subsection{Data Collection}

Standard questionnaire was developed and the data were collected by face to face interview. After filling the questionnaire, an empty plastic container was provided to the all of female inhabitants for collecting stool. The stool samples were processed and prepared for microscopic examination in the laboratory of the Department of Zoology, University of Dhaka.

\subsection{Laboratory analysis}

To find out the prevalence of intestinal parasites, stool samples were collected and were examined in laboratory. The Formol-Ether concentration technique was performed according to the method described by Cheesbrough (1987). $1 \mathrm{~g}$ of faecal sample was mixed with $4 \mathrm{ml}$ of formol water, again 3-4 $\mathrm{ml}$ of $10 \%$ formol water was added and mixed by shaking for about 20 seconds then strained it. 3-4 $\mathrm{ml}$ formol ether was added with sieved suspension in a conical tube and mixed for 1 minute, it was then centrifuged at $3000 \mathrm{rpm}$ for $1-2 \mathrm{~min}$, the parasites were sedimented to the bottom of the tube. The sediment was examined using 10X objective with the condenser. The 40X objective was used to identify the small cysts and eggs. And the data generated was analyzed by the SPSS Software-17 for mean analysis.

\section{Results and Discussion}

\subsection{Prevalence of intestinal parasites}

During the present investigation out of 900 samples, $66.22 \%$ females were found to be infected with intestinal parasites which was lower than the findings of Muttalib et al. (1976) (99.03\%), Suguti et al. (1985) (86.8\%) in Nepalese people, Uddin and Khanum (2008) (84.21\%) in Comilla and Dhaka. Alternatively the present prevalence is higher than the findings of Peruzzi et al. (2006) (13.24\%), Chandrashekhar et al. (2005) (21.3\%), Al-Madani and Mahfouz (1995) (46.5\%), and Ahmed and Hady, (1989) (10.94\%). Ikeh et al. (2006) found 50.5\% prevalence, Rao et al. (2003) reported 57\%, Tang and Luo (2003) recorded 51.7\%, Reinthaler et al. (1988) reported 62\%, Farag (1985) found 53\%, Chowdhury (1978) showed 52.76\% and Huq and Shaikh (1976) found $65 \%$ prevalence, above these studies which were closely related with our findings. Hygienic conditions are very poor in slum area that's why prevalence was found highest.

A total of twenty six parasite species were identified from the samples. Among them ten were protozoans such as Entamoeba histolytica, Entamoeba coli, Endolimax nana, Iodamoeba butschlii, Chilomastix mesnili, Trichomonas hominis, Enteromonas hominis, Giardia intestinalis, Isospora hominis, Balantidium coli. Six cestodes such as Diphyllobothrium latum, Taenia saginata, Echinococcus granulosus, Hymenolepis nana, Hymenolepis diminuta, Dipylidium caninum. Four trematodes such as Fasciola hepatica, Fasciolopsis buski, Clonorchis sinensis, Paragonimus westermani. And six nematodes such as Ascaris lumbricoides, Trichuris trichiura, Ancylostoma duodenale (egg), Ancylostoma duodenale (larvae), Strongyloides stercoralis (larvae), Enterobius vermicularis (egg), Capillaria spp. Begum and Rahman (1975) found five species of protozoa (E. 
histolytica, E. coli, Endolimex nana, Iodamoeba butschlii, G. lamblia) and four species of helminth (A. lumbricoides, A. duodenale, T. trichiura and E. vermicularis) predominant in Bangladesh. Khaled (1983) found eight species of intestinal parasites in members of Bangladesh rifles. These were: Entamoeba histolytica, Giardia intestinalis, Ascaris lumbricoides, Trichuris trichiura, Strongyloides stercoralis, Humenolepis nana, Enterobius vermicularis and Hookworm. In Indonesia, Higgins et al. (1984) studied human intestinal parasitic infections. They listed Entamoeba coli, Entamoeba histolytica, Entamoeba hartmanni, Endolimax nana, Iodamoeba butschlii, Chilomastix mesnili, Giardia lamblia, Ascaris lumbricoides, Trichuris trichiura and Necator americanus. In Nigeria, Alakija (1986) reported E. coli, T. hominis, E. nana, E. histolytica, I. butschilii, G. lamblia, B. coli, A. lumbricoides, hookworm, T. trichiura, S. stercoralis, Taenia and S. mansoni from rural people.

Among parasitic groups, nematode showed the highest prevalence $(57.55 \%)$, then cestode $(38.67 \%)$, protozoa $(19.22 \%)$, and lowest was found in trematode (4.11\%) (Figure1). So helminth infections were recorded to be higher compared to protozoan infection which is incompatible with the previous published result such as Hafez et al. (1986) reported $14.9 \%$ of prevalence for protozoans and $9.5 \%$ for helminth in Riyadh, Saudi Arabia and Alakija (1986) also found higher (44.2\%) prevalence of protozoa than helminth (22.4\%) in Nigeria. Highest prevalence of helminth found in some study like Muazzam and Ali (1968) showed 67\% of prevalence among children of East Pakistan and Saha and Chowdhury (1981) reported 75\% of children (unde 5 years) of Rangpur and Dinajpur districts. Reinthaler et al. (1988) stated that contaminated drinking water is clearly the main source of the high levels of protozoan infection. But in the present study higher rate of parasitization with helminth suggest that these parasites have highly effective distribution and contact mechanism from one person to another.

The prevalence of different species of intestinal parasites varied from one another. In the present investigation, prevalence of cyst of Entamoeba histolytica was highest (10.44\%) and common Giardia intestinalis was 4\% (Figure 2). The prevalence seems to be high in some study such as Aza et al. (2003) recorded 21\%, Azian et al. (2007) noted 26.2\% E. histolytica in Pahang, Malaysia. Some result was found comparatively lower than the present study such as Hamimah et al. (1982) found 2.3\% prevalence in Kualalumpur, Malaysia, Azam et al. (2007) observed 3.6\% in Gazipur and Khanum et al. (2014) estimated 4.61\%. The prevalence of G. intestinalis found in the present study, was also relatively low compared to 25\% in Turkey (Ozcelik et al. 1995), 18.5\% in Nepal (Reddy et al. 1998) and 11.67\% in Thai orphans (Popruk et al. 2011). But Hamimah et al. 1982 (2.6\%) and Khaled, $1983(0.4 \%)$ recorded lower rate of infection of G. intestinalis than this study. Khanum et al. (2014) estimated $3.71 \%$ prevalence of $G$. intestinalis and Reinthaler et al. (1988) found 4.2\%, which were close to present study.

Among cestodes, Hymenolepis nana recorded as the highest (22.78\%) prevalent parasite, then Taenia saginata (10.33\%) (Figure 3). This was higher than the findings of Omar et al. (1991) (3.0\% prevalence of $H$. nana in Abha, Saudi Arabia), Jalili and Cerven 1993 (6.0\% in the province of Afghanistan), Machado and Costacruz (1998) (6.7\%), Azazy and Aitiar 1999 (2\% in Yemen), Mirdha and Samantray (2002) (9.9\% in India) and Muscat et al. (2004) (4.9\% in Bangladesh). Rim et al. (2003) investigated that the prevalence of Teania spp. was only $0.6 \%$ in Laos that was lowest than present study.

Among trematodes, prevalence of Fasciolopsis buski was observed the highest (2.11\%) (Figure 4). Idris (1979) showed that the prevalence of $F$. buski was $36.16 \%$ in a village named Maradia near Dhaka, whereas Nahar (1973) showed that the prevalence was only $0.31 \%$ in Dhaka city. This observation reflects that the infection by F. buski might have focal endemicity. According to Graczyk et al. (2001), lower incidences with focal endemicity are observed in Taiwan, Bangladesh, India and Thailand.

Among the nematode parasites, Ascaris lumbricoides showed the highest (38\%) and Trichuris trichiura was the second highest (30\%) common parasite (Figure 5). Thuriaux (1973) reported 22\% Ascaris lumbricoides in Yemen Arab Republic, Obiamiwe (1977) recorded 19.5\% in Benin City, Nigeria, both results were found comparatively lower than the present findings. Elkins (1984) found 94\% in Madras, Osazuwa et al. (2011) determined $75.6 \%$ in Nigeria which was quite different from the findings of the present work; Alam and Khanum (2005) found 34.38\% in Dhaka, Uddin and Khanum (2008) showed 37.5\% in Gazipur, Bangladesh, these results were close to present findings. The highest prevalence of A. lumbricoides is mainly attributed to high rate of egg production by the females, longevity of the eggs, use of night soil, poor personal hygiene and consumption of unclean vegetables. Shield et al. (1981) showed 15.9\% Trichuris trichiura in Papua New Guinea, Hafez et al. (1986) reported 2.5\% of people in Saudi Arabia, these prevalence were lower than the present finding. According to Ejezie (1981) $75.8 \%$ and Kobayashi et al. (1996) 43.8\% was suffering from trichuriasis, both were higher than present study. Reinthaler et al. (1988) recorded 23.2\% in Nigeria and Wani et al. (2008) $27.92 \%$ in Kashmir valley, both were close to present findings. 


\subsection{Prevalence of parasites in different study areas}

In 12 study areas, highest prevalence was found (87.5\%) in Kamrangichar, and lowest 30\% found in Hajaribag (Figure 6). Kamrangichar is an island Thana surrounded by mainly Buriganga River. The population is very dense in this area they live in unhygienic environment, there is lack of fresh water supply, lack of sanitary latrines, defaecate in open areas, they walk barefooted most of the time and most important this area is surrounded by polluted Buriganga River which facilitates the growth of intestinal parasite. Hajaribag was urban Thana of Dhaka metropolitan city where chemical pollution occurred mostly as many chemical factories found there; as a result survival of parasite's egg and cyst in that environment is very low because of that chemical pollution that's why lower prevalence of infection observed there.

In different study areas, the prevalence of protozoan parasites was comparatively higher in Shahidullah hall (43.33\%). In case of cestodes, highest prevalence was found in Kamrangichar (71.25), in case of trematodes, highest observed in Hajaribag (15\%) and among nematodes, highest recorded in Moghbazar (70\%) (Figure 7).

\subsection{Parasitic prevalence in age groups}

Considering all of the four age groups, the highest prevalence $(75.65 \%$ ) was found in children group (1 to 15 years) (Figure 8). Relationship between age and prevalence of parasitic infection $(\mathrm{r}=-0.284, \mathrm{p}=0.716)$ was not significantly correlated. Inverse correlation implies that as age increase prevalence tend to decrease due to better immune response in upper ages. Similar high prevalence (73.3\%) was found in children by Ara et al. (1997). According to Steketee (2003) and Garzon (2003), children are the worst affected. This could be due to the fact that child are exposed to environmental hazard favoring parasitic infections. In another study by Uddin et al. (2005), highest (87.50\%) was also noted among aged 12-14 years, Singh et al. (1984) recorded a maximum of 92.5\% from 5 to 9 years of age but Khanum et al. (2010) found lowest prevalence in 08-10 years age group. The infestation of nematodes found highest in all age groups, among children (28.49\%) and adult age group $(10.40 \%)$, protozoa were the $2^{\text {nd }}$ highest infestation group. Highest infestation $(13.98 \%)$ of cestodes was observed in children group (Figure 9).

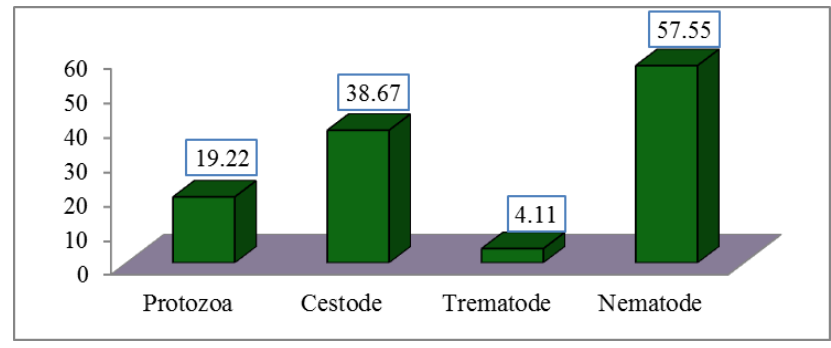

Figure 1. Overall prevalence of different parasitic groups.

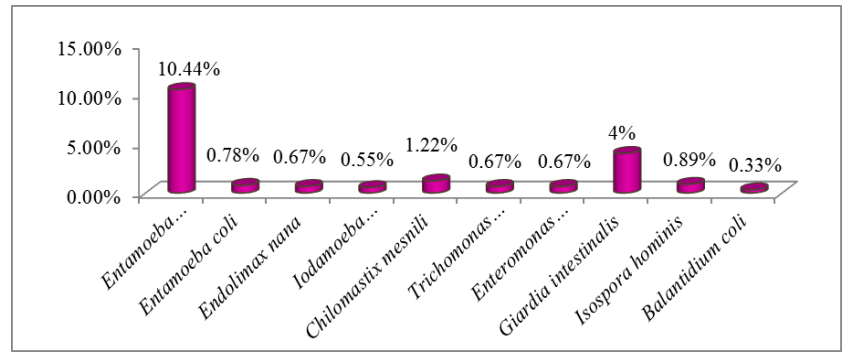

Figure 2. Prevalence of protozoan parasites found in female inhabitants.

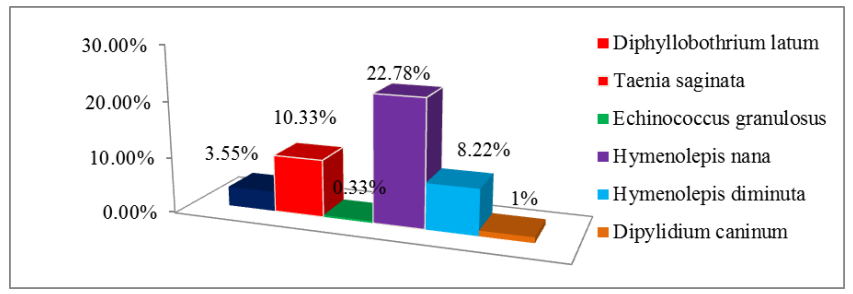

Figure 3. Prevalence of cestode parasites found in female inhabitants. 


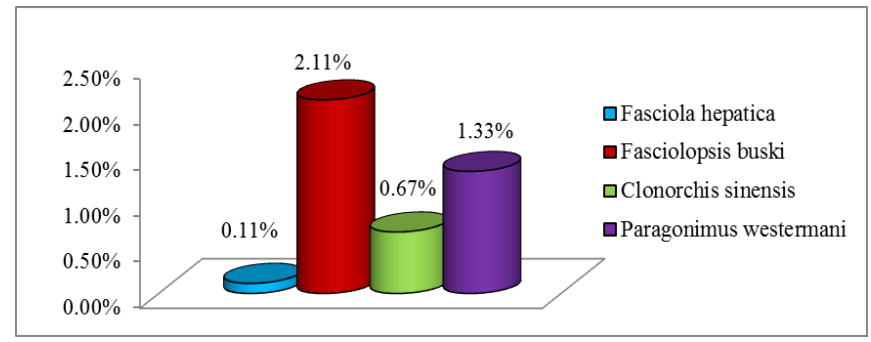

Figure 4. Prevalence of trematode parasites found in female inhabitants.

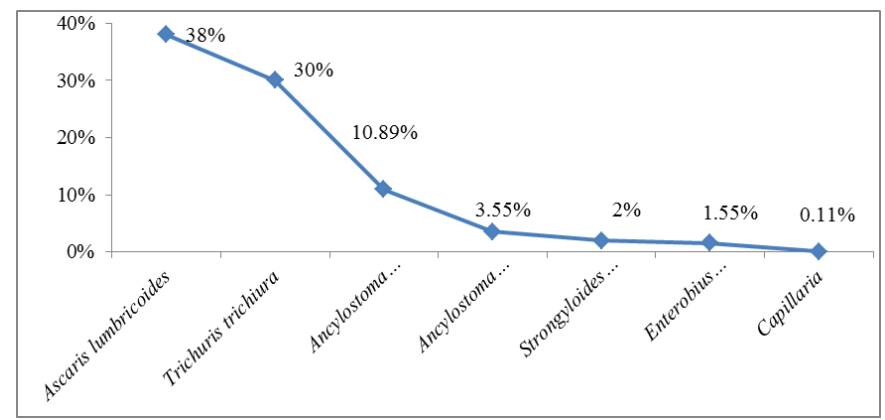

Figure 5. Prevalence of nematode parasites found in female inhabitants.

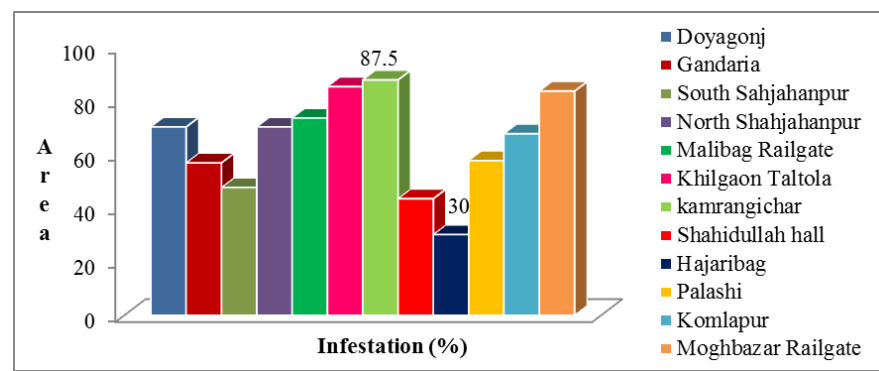

Figure 6. Prevalence of intestinal parasites among the female inhabitants in different study areas.

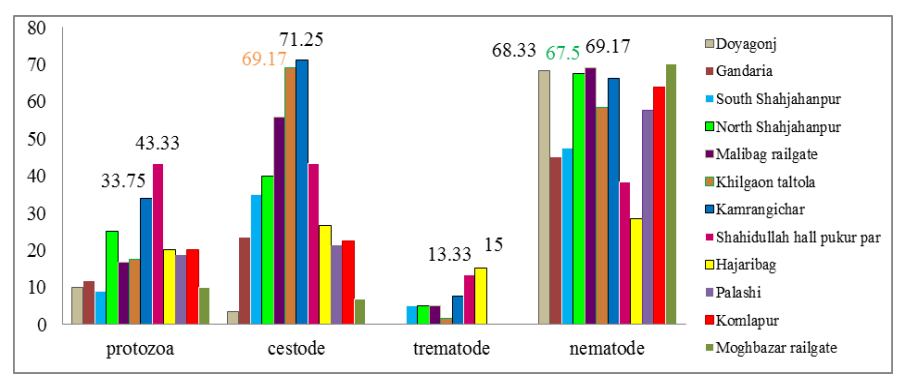

Figure 7. Prevalence of different parasitic groups among female inhabitants in different study areas.

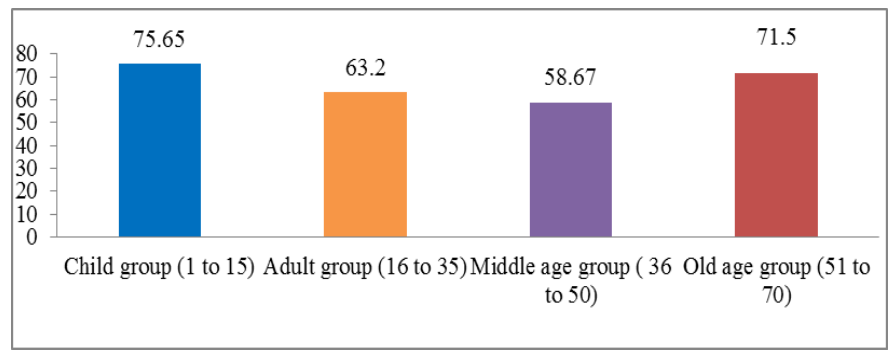

Figure 8. Overall prevalence of parasitic infection in different age groups among the female inhabitants. 


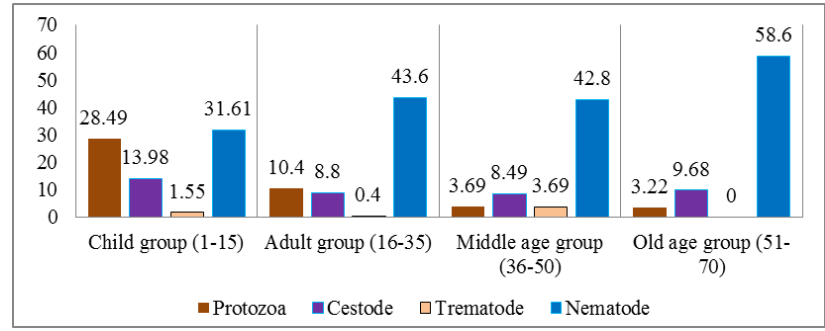

Figure 9. Overall prevalence of parasitic group in different age among female inhabitants.

\section{Conclusions}

The prevalence of helminthiasis and protozoan infection is widespread in Bangladesh. The female inhabitants of the slum areas were more vulnerable to parasitic infestation due to the differences in hygienic conditions, rate of literacy, malnutrition, status of anaemia, and prevailing socioeconomic condition. Under above circumstances incidence of intestinal parasites is likely to be common. Information on the prevalence and intensity of human intestinal parasites of the people of Dhaka city is very meager. Such information is necessary in planning the control of parasitic infection.

\section{Conflict of interest}

None to declare.

\section{References}

Ahmed MM and HM El Hady, 1989. A preliminary survey of parasitic infections and nutritional status among school children in Riyadh, Saudi Arabia. J. Egypt Soc. Parasitol., 19: 101-105.

Alakija W, 1986. Prevalence of intestinal parasitic disease agents in stools of people in a rural area of Nigeria. Ann. Trop. Med. Parasitol., 80: 545-547.

Alam MS and H Khanum, 2005. Infection of Ascaris lumbricoides and Trichuris trichiura among the children of two slum areas in Dhaka city. Bangladesh J. Zool., 33: 89-94.

Al-Madani AA and RM Mahfouze, 1995. Prevalence of intestinal parasitic infections among Asian female housekeepers in Abha district, Saudi Arabia. Southeast Asian J. Trop. Med. Public Health., 26: 135- 137.

Ara R, KZ Mamun, S Tabassum and LFA Banu, 1997. Helminthiasis and it's impact on nutritional status of children. JOPSOM, 16: 44-48.

Aza N, S Ashley and J Albert, 2003. Parasitic infections in human communities living on Ringes of the Crocker Range Park Sabah, Malaysia. Asian review of biodiversity and environmental conservation (ARBEC). http://www.arbec.com .my/pdf/art11/janmar03.pdf.

Azam SAS, MMR Bhuiyan, MZ Choudhury and KA Miah, 2007. Intestinal Parasites and Sanitary Practices among the Rural Children. TAJ. Rajshahi., 20: 01-05.

Azazy AA and AS Aitiar, 1999. A study on intestinal and blood parasites among school children in Sana province, Yemen. Saudi. Med. J., 20: 422-424.

Azian NMY, YM San, CC Gan, MY Yusri, Y Nurulssyamzawaty, AH Zuhaizam, MN Maslawati, I Norparina and I Vythilingam, 2007. Prevalence of intestinal protozoa in an aborigine community in Pahang, Malaysia. Trop. Biomedicine., 24: 55-62.

Banu H, J D'Silva and N Islam, 2003. Epidemiological factors and pinworm infection in children. Bangladesh J. Zool., 31: 243-246.

Begum NN and KM Rahman, 1975. Comparative finding of helminth and protozoa by various techniques. Bang. Med. J., 4: 8-12.

Bundy DAP and ES Cooper, 1989. Trichuris and trichuriasis in humans. Adv. Parasitol., 28:107-73.

Bundy DAP, A Hall, GF Medley and L Savioli, 1992. Evaluating measures to control intestinal parasitic infections. World Health Stat Q., 45: 168-179.

Chandrashekhar TS, HS Joshi, M Gurung, SH Subba, MS Rana and PG Shivananda, 2005. Prevalence and distribution of intestinal parasitic infestations among school children in Kaski District, Western Nepal. JBR, 4: 78-82.

Cheesbrough M, 1987. Medical Laboratory Manual for Tropical Countries. Blackworth Co. Publishers., 570 pp.

Chowdhury MR, 1978. Intestinal parasite infection in privileged class of Dhaka population, Bangladesh. Armed Forces Med. J., 4: 5-12.

D'Silva J, H Banu and N Islam, 2003. Pinworm infection in children and their personal habits. Dhaka Univ. J. Biol. Sci., 12: 193-198. 
Ejezie GC, 1981. The parasite disease school children in Lagos State, Nigeria. Acta Tropica., 38: 79-84.

Elkins DB, 1984. A survey of intestinal helminths among children of different social communities in Madras, India. Trans. R. Soc. Trop. Med. Hyg., 78: 132-133.

Farag HF, 1985. Intestinal parasites in the populations of the Yemen Arab Republic. Trop. Geogr. Med., 37: 2931.

Garcia LS, 2001. Diagnostic medical parasitology. ASM Press, Washington, DC, 872 pp.

Graczyk TK, RH Gilman and B Fried, 2001. Fasciolopsiasis: is it a controllable food-borne disease? Parasitol. Res., 87: 80-83.

Guerrant RL, JM Hughes, LM Lima and J Crane, 1990. Diarrhea in developed and developing countries: magnitude, special settings, and etiologies. Rev. Infect. Dis., 12: 41-50.

Hafez MMAA, NEI Kady, AS Bolbol and MH Baknina, 1986. Prevalence of intestinal parasitic infections in Riyadh, Saudi Arabia. Ann. Trop. Med. Parasitol., 80: 613-634.

Hamimah I, M Zahedi and AJ Ainiyah, 1982. The prevalence of intestinal parasites among children at the General Hospitals, Kuala Lumpur, Malaysia. Med. J. Malaysia., 37: 373-377.

Higgins DA, DJ Jenkins, L Kurniawan, S Purnomo Harun and SS Juwono, 1984. Incidence of intestinal parasite in children of different socio-economic population of Dhaka city. BMRC Bull., 11: 27-29.

Huq N and A Sheikh, 1976. Incidence of intestinal parasite in children of different socio-economic population of Dhaka City, Bangladesh. Bang. Med. Res. Council., 11: 20-26.

Idris M, 1979. A study on infestation with Fasciolopsis buski in children at Maradia, a rural area close to Dacca city. Thesis for M.Phill Microbiology, Dacca University. pp. 5-8.

Ikeh E, M Obadofin, B Brinderio, C Baugher, F Frost, D Vanderjagt and R Glew, 2006. Intestinal parasitism in rural and urban areas of North Central Nigeria: An update. Int. J. Microbiol., 2: 1-5.

Islam AFM, M Sadeque, K Biswas, N Ahmed and G Mahmood, 1975. Helminthiasis and anaemia in student of Dhaka University. Bang. Med. Res. Council Bull., VII: 40-45.

Jalili NA and D Cerven, 1993. The parasitic infections of soldiers of a division in the province of Baghlan (Afghanistan) recorded during 1988. Biologia., 49: 615-618.

Khaled GA, 1983. Incidence of intestinal parasitic infection in Bangladesh Rifles. Bang. Armed Force Med. J., 7: 29-31.

Khanum H, MA Masum, R Kabir, RR Day and R Farhana, 2008. Comparison of Direct Agglutination Test (DAT) and aldehyde Test (AT) in serodiagnosis of visceral leishmaniasis. Bangladesh J. Zool., 36: 93-99.

Khanum H, MR Islam and S Parvin, 2010. Occurrence of eggs and larvae of gastrointestinal nematodes in nails of street inhabitants in Dhaka city. J. Life Earth Sci., 5: 75-79.

Khanum H, MM Rahman, MH Uddin, S Alam, F Rahman and R Farhana, 2010. Intestinal Parasitic Infestation among the Outdoor Patients of Dhaka University Medical Centre, Bangladesh. Univ. J. Zool. Rajshahi Univ., 28: 45-49.

Khanum H, F Rahman and RF Zaman, 2014. Occurrence of intestinal parasites among the teachers, students and staffs of Dhaka University. J. Asiat. Soc. Bangladesh sci., 39: 239-246.

Kobayashi J, B Vannachone, A Xeutvongsa, K Manivang, S Ogawa, Y Sato and K Pholsena, 1996. Prevalence of intestinal parasitic infection among children in two villages in Lao PDR. Southeast Asian J. Trop. Med. Public Health, 27: 562-565.

Kuntz RE, 1960. Intestinal protozoa and helminths in school children of Dacca, East Pakistan (East Bengal). Am. J. Trop. Med. Hyg., 9: 168-172.

Machado ER and JM Costacruz,1998. Strongyloides stercoralis and other enteroparasites in children at Uberlandia city, state of Minas Gerais, Brazil. Memorias Do. Inst. Oswaldo Cruz., 93: 161-164.

Mirdha BR and JC Samantray, 2002. Hymenolepis nana: a common cause of paediatric diarrhoea in urban slum dwellers in India. J. Trop. Pediatr., 48: 331-334.

Mitra SN, MN Ali, SH Islam, AR Cross and T Saha, 1994. Bangladesh demographic and health survey 19931994. Calverton, Maryland USA: National Institute of Population Research and Training (NIPORT), Mitra and Associates and Macro International Inc.

Muazzem MG and T Ali, 1968. Incidence of intestinal parasites among children of East Pakistan. Medicus., 25: 215-221.

Muscat M, KZ Mamun, S Tabassum, AA Ahmed and P Shears, 2004. Environmental risk factors and intestinal parasitic carriage in Bangladesh. Journal of Dhaka Medical College, 13: 1-7.

Muttalib MA, N Islam and S Islam, 1976. Prevalence of intestinal parasite in rural children of Bangladesh. Bangladesh Med. J., 5: 9-27. 
Nahar BN, 1973. Study of the incidence of intestinal parasites in Bangladesh. M. Phil dissertation. Department of Microbiology and Immunology, BSMMU.

Obiamiwe BA, 1977. The pattern of parasitic infection in human gut at the specialist hospital Benin City, Nigeria. Ann. Trop. Med. Parasitol., 71: 35-43.

Omar MS, HAH Abuzeid and AAR Mahfouz, 1991. Intestinal parasitic infection in school children of Abha, Saudi Arabia. Acta Trop., 48: 195-202.

Osazuwa F, OM Ayo and P Imade, 2011. A significant association between intestinal helminth infection and anaemia burden in children in rural communities of Edo state, Nigeria. North Am. J. Med. Sci., 3: 30-34.

Ozcelik S, O Poyraz, G Saygi and S Osturkcan, 1995. Prevalence of intestinal parasites in children of the orphanage in Sivas, Turkey. Indian pediatrics. 32: 230-232.

Pan American Health Organization / PAHO. 1997. Communicable Diseases: Control of Intestinal Parasitosis. Available at: http://165.158.1.110/english/hcp/hctpep01.htm. Accessed 16 August 2005.

Peruzzi S, C Gorrini, G Piccolo, A Calderaro, G Dettori and C Chezzi, 2006. Prevalence of intestinal parasites in the area of Parma during the year 2005. Acta Biomed., 77: 147-115.

Pillai DR and KC Kain, 2003. Common Intestinal Parasites. Current Treatment Options in Infectious Diseases, 5: 207-217.

Popruk S, K Thima, R Udonsom, P Rattaprasert and Y Sukthana, 2011. Does Silent Giardia Infection Need Any Attention? The Open Tropical Medicine Journal, 4: 26-32.

Rim HJ, JY Chai, DY Min, SY Cho, KS Eom, SJ Hong, WM Sohn, TS Yong, G Deodato, H Standgaard and B Phommasack, 2003. Prevalence of intestinal parasite infections on a national scale among primary school children in Laos. Parasitol. Res., 91: 267-272.

Rao VG, MC Aggrawal, R Yadav, SK Das, LK Sahare, MK Bondley and AR Minocha, 2003. Intestinal parasitic infections, anaemia and under nutrition among Tribal adolescent of Modhya Pradesh. Indian J. Community Med., 28: 1-5.

Reinthaler FF, F Mascher, G Klem and W Sixl, 1988. A survey of gastrointestinal parasites in Ogun State, southwest Nigeria. Ann. Trop. Med. Parasitol., 82: 181-184.

Saha B and AB Chowdhury, 1981. Helminthic infection in under five children in Rangpur and Dinajpur dristricts. Bangladesh Med. J., 16: 7-11.

Shield JM, D Smith and P Heywood, 1981. Prevalence of alimentary helminthiasis and its association with nutritional status in children of under 5 years old in the high lands of Papua New Guinea. PNG Med., 24: 4044.

Singh DS, RK Hotchandani, S Kumar, JS Seecatt, PK Srivastava and KN Udupa, 1984. Prevalence and pattern of intestinal parasitism: a rural community of Varanasi. Indian J. Prev. Soci. Med., 15: 1-8.

Sprong H, SM Caccio and JWB Van Der Giessen, 2009. Identification of zoonotic genotypes of Giardia duodenalis. PLoS. Negl. Trop. Dis., 3: e558.

Steketee RW, 2003. Pregnancy, nutrition and parasitic diseases. Journal of Nutrition., 133: 1661-1667.

Suguti S, Y Tongu, S Lnatomi and HD Pradhan, 1985. A survey on human parasite infections in Nepal. Japanese Journal of Parasitology, 34: 285-292.

Tang N and NJ Lou, 2003. A cross-sectional study of intestinal parasitic infections in a rural district of West China. Can .J. Infect. Dis., 14: 159-162.

Thuriaux, MC, 1973. Distribution of intestinal helminths in children in the Yemen Arab Republic. Trop. Geogr. Med., 25: 45-50.

Uddin MH, MM Rahman and H Khanum, 2005. Hemoglobin level among adolescent girls and it's relation to intestinal parasites. Bangladesh J. Zool., 33: 183-187.

Uddin $\mathrm{MH}$, and $\mathrm{H}$ Khanum, 2008. Intestinal parasitic infestation and anaemic status among the adolescent boys in Bangladesh. Univ. J. Zool. Rajshahi Univ., 27: 63-65.

Victora CG, SR Huttly and S Fuchs, 1993. International differences in clinical patterns of diarrheal deaths: a comparison of children from Brazil, Senegal, Bangladesh, and India. J. Diarrh. Dis. Res. 11: 25-9.

Wani SA, F Ahmad, SA Zargar, ZA Dar, PA Dar, H Tak and BA Fomda, 2008. Soil-transmitted helminths in relation to hemoglobin status among school children of the Kashmir Valley. J. Parasitol., 94: 591-593.

World Bank, 1993. World Development Report: Investing in Health. Oxford University Press, New York, NY.

World Health Organization, 1990. Global estimates for health situation assessment and projection. Geneva.

World Health Organization, 2001. Infectious Diseases Homepage. Intestinal parasites. @ http://www.who.intpara.html.

World Health Organization, 2002. Disease trends. Available from: www.who.int/ctd/intpara/disease.php. 